\title{
Article \\ Studies with Rheological Behavior of Composite Lithium-Based Magnetorheological Grease
}

\author{
Hua Yan ${ }^{1}$, Pingyang $\mathrm{Li}^{2, *(\mathbb{D}}$, Chi Duan ${ }^{2}$ and Xiaomin Dong ${ }^{2}$ \\ 1 School of Intelligent Manufacturing Engineering, Chongqing College of Architecture and Technology, \\ Chongqing 401331, China; yanhuacq@sina.com \\ 2 State Key Laboratory of Mechanical Transmission, Chongqing University, Chongqing 400044, China; \\ 20162818@cqu.edu.cn (C.D.); xmdong@cqu.edu.cn (X.D.) \\ * Correspondence: 20170713098t@cqu.edu.cn
}

check for updates

Citation: Yan, H.; Li, P.; Duan, C.; Dong, X. Studies with Rheological Behavior of Composite Lithium-Based Magnetorheological Grease. Metals 2021, 11, 1826. https://doi.org/10.3390/met11111826

Academic Editor: Jean-Michel Bergheau

Received: 24 October 2021 Accepted: 10 November 2021 Published: 13 November 2021

Publisher's Note: MDPI stays neutral with regard to jurisdictional claims in published maps and institutional affiliations.

Copyright: (c) 2021 by the authors. Licensee MDPI, Basel, Switzerland. This article is an open access article distributed under the terms and conditions of the Creative Commons Attribution (CC BY) license (https:// creativecommons.org/licenses/by/ $4.0 /)$.

\begin{abstract}
Magnetorheological (MR) grease has advantages of the anti-settlement behavior and excellent sealing property compared with conventional MR materials. However, the rheological behaviors of MR effect and shear yield stress are too small to limit the further applications with MR grease. This paper proposes a composite lithium-based MR grease with boric acid-hydroxyl stearic acid to improve the rheological behaviors. Eight different samples of composite lithium-based MR grease with different ratios of mass between lithium stearate and lithium borate are prepared by the saponification method. The rheological behaviors are tested and discussed with qualitative and quantitative analysis. The experimental results show that the off-state viscosity reduces with the decrement of the ratio of mass under low shear rate which changes from 68.7 Pa.s to $16.5 \mathrm{~Pa} \cdot \mathrm{s}$. Lithium stearate content has more effects with off-state viscosity. Based on the Herschel-Bingham model, the shear stress of composite lithium-based MR grease can be improved dramatically by adjusting the ratio of mass which is increased by $170 \%$ under the magnetic flux density of $0.2 \mathrm{~T}$. Compared with single lithium-based MR grease, the maximum yield shear stress is increased by $166.7 \%$ at off-state and the maximum MR effect is also increased by $19.1 \%$. The MR effect can reach $23,600 \%$ with a specific mass ratio of the composite MR grease. The experimental results validate that the feasibility of the performance improvement by the composite lithium-based MR grease.
\end{abstract}

Keywords: composite lithium-based magnetorheological grease; ratio of mass; rheological behavior

\section{Introduction}

Since the magnetorheological (MR) fluid has been developed, it has attracted much attention as a typically smart and intelligent material due to its perfect controllable rheological properties with an external magnetic field. Under the applied magnetic field, the MR fluid can be transformed from the liquid state to the solid-like state with milliseconds. The yield stress and shear viscosity can be controlled by the applied currents. MR fluid has been utilized in many different engineering fields [1-3], with vehicle suspension [4], cable-stayed bridges [5], semi-control [6-8], seals [9,10], and machine tool isolations [11]. However, because of the huge density difference between the magnetic particles and carrier liquids of MR fluid, the properties of sedimentation with MR fluid is of great significance in further studies and applications. Magnetic particles form an agglomeration, and the re-dispersion is unachievable if the MR fluid is rested for a long time. Besides these, the sedimentation stability properties are difficult to be resolved ultimately by additives and other methods. MR grease is one of the typical MR materials which has a thixotropic crosslink structure. Based on the unique thixotropic crosslink structure of the carrier grease, the settlement problem has been solved by MR grease [12-14]. And MR grease has a better performance with anti-leakage, long-term steady stability, and oxidation stability, etc. MR grease shows a better development compared with MR fluid in the engineering applica- 
tions which especially require keep stabilization for a long term, such as seismic dampers and shock absorbers of buildings.

At present, there is much research investigating MR grease. While most investigations mainly focus on the lithium-based MR grease. In general, the magnetic particles mixed with the commercial grease directly to prepare the valvoline multi-purpose grease $[15,16]$. The prepared MR grease showed good lubrication performance in flow mode. The kerosene was also used in MR grease. The kerosene can effectively decrease the viscosity of the MR grease with soft magnetic particles for obtaining a well-dispersed suspension [17]. Mohamad et al. [18] carried out comparative experiments with particle shapes. It is shown that the bidisperse MRG with plate-like CI particles exhibits an increase in the initial apparent viscosity as well as stiffness property compared to the MR grease with spherical particles only. Wang et al. [19] studied the effects of silicone oil viscosity and carbonyl iron particle weight fraction and size on shear yield stress for MR grease. It is shown that the shear rate and temperature have significant importance with MR properties [20,21]. Besides these, the preparation process was closely related to the MR performance. The lithium-based MR grease with a damping effect was prepared by a one-step process. The results show that the MR grease has the characteristics of shear thinning. The shear yield stress and magnetic field strength have a power-law relationship with different thickener content [22]. An unconventional method which consisted of seven steps was used to prepare MR grease and the results have shown that shear thinning of MR greases are closely related to magnetic field strengths and CIPs size has an insignificant effect on shear-thinning [23]. Mohamad et al. [24] prepared a new MR grease with plate-like carbonyl iron particles. It was found that the external magnetic field strength and volume fraction of magnetic particles had a significant effect on the MR properties. According to current studies with MR grease, the maximum shear stress with the prepared MR grease is only $49.7 \mathrm{kPa}$ while magnetic flux density B was $0.53 \mathrm{~T}$, and the shear rate $\dot{\gamma}$ was fixed at $400 \mathrm{~s}^{-1}$ [15]. The maximum MR effect only reached $2350 \%$ [22]. Compared with the conventional MR fluid, the shear yield stress with MR grease was so minimal that its applications have been limited greatly in many fields. Besides these, the shear yield stress and MR effect are hard to balance. The higher off-state viscosity of MR grease will result in a higher off-state damping force and a lower MR effect.

In order to improve the MR properties of MR grease, the optimization of carrier grease was the most familiar and effective way. However, there were few relevant studies with the composite lithium-based MR grease. Yao et al. [25] found that the apparent viscosity of lithium-based MR grease decreases with the increase of shear rate, and the decrease is related to temperature. Wang et al. [19] studied that the force of MR grease under quasi-static shear decreases at first. And then, it maintains constant along with the increase of shear strain. The critical strain is affected by the magnetic field strength and CI particles content. Zeng et al. [26] analyzed the effects of different thickeners, the viscosity of base oil, and additives on the performance of the grease. Compared with five different greases, experimental results showed that soap fiber length, thickness, and three-dimensional structure determined the colloidal properties of grease. Yan et al. [27] proposed a novel composite lithium-based MR grease with several thickening agents. The maximum valve of MR effect was approximately 13,000\% with $60 \mathrm{wt} \%$ ferromagnetic particles. Mohamad et al. [28] prepared MR grease with different content of iron particles. The maximum yield stress and MR effect can reach about $52.7 \mathrm{kPa}$ and $952.38 \%$. Based on the present research status, the differences among the microstructure with different carrier greases have a great impact on the MR properties of MR grease [29]. Therefore, the influence of key parameters with composite MR grease is not enough. The rheological performance with shear yield stress and MR effect is too small to use in engineering applications. There is an urgent need to prepare a novel composite MR grease to meet the balance of shear stress and MR effect.

In a word, based on these motivations, the main technical contribution of this paper was that a novel composite lithium-based MR grease with lithium stearate and lithium 
borate had been prepared and experimented with to improve the MR behaviors. Eight samples with different mass ratios of thickeners were prepared. Rheological properties were measured in the shear model by the conventional rheometer. The off-state viscosity and yield stress were comparatively analyzed. Besides these, the dynamic viscoelastic prosperities of the proposed composite lithium-based MR grease were quantitatively analyzed in the oscillation model. The storage modulus and loss modulus were discussed with different mass ratios and external magnetic excitations. The feasibility of composite lithium-based MR grease was validated by comparative experiments.

\section{Experiments}

\subsection{Preparation of $M R$ Grease}

In this study, MR grease was prepared by mixing the carbonyl iron powders (CIPs, provided by Beijing Xingrognyuan Technology Co., Ltd. with an average radius of $5 \mu \mathrm{m}$ ) into silicone oil (PMX-200, provided by Dow silicone Co., Ltd. Zhangiiagang, China). Lithium-based thickener (provided by Aisaike lubricating Co., Ltd. Shenzhen, China) which is mainly composed of lithium stearate was the main additive. Besides these, lithium hydroxide (AR level, provided by Runxin Experimental Instrument Co., Ltd., Dezhou, China), boric acid (AR level, provided by EBI Chemical Reagent Co., Ltd., Shanghai, China), and diphenylamine (AR level, Huakai resin Co., Ltd., Jining, China) were used in the preparation process as other additives.

Firstly, a specified amount of silicone oil was divided equally into three parts. The first part of silicone oil was mixed with the appropriate amount of water and heated to $80-100{ }^{\circ} \mathrm{C}$. And then, the lithium-based thickener, lithium hydroxide, and boric acid were added into the mixed liquid and continually heated to $100-120^{\circ} \mathrm{C}$ for $30 \mathrm{~min}$. Next, the second part of silicone oil and a specified amount of diphenylamine which was used as an antioxidant were added to the mixture at $130-140{ }^{\circ} \mathrm{C}$ and dehydrated for $60 \mathrm{~min}$. After dehydration, carbonyl iron powders were added into the mixture and heated to $150-180^{\circ} \mathrm{C}$ for $45 \mathrm{~min}$. And then, the low-temperature thickening is available. What's more, the temperature of the mixed liquid was raised to $180-200^{\circ} \mathrm{C}$ for $15 \mathrm{~min}$ to complete the hightemperature thickening. Finally, the third part of silicone oil was added into the mixed liquid with air cooling. The mixture was ground and encapsulated as the prepared MR grease when it was cooled to approximately $120^{\circ} \mathrm{C}$. The preparation is shown in Figure 1 . As shown in Table 1, according to the different mass ratios of lithium stearate to lithium borate. The lithium borate was produced by the reaction, a total of 8 samples were prepared. Among these samples, sample 1 and sample 8 were prepared with a single thickener which was used to comparatively analyze with composite lithium-based MR grease.

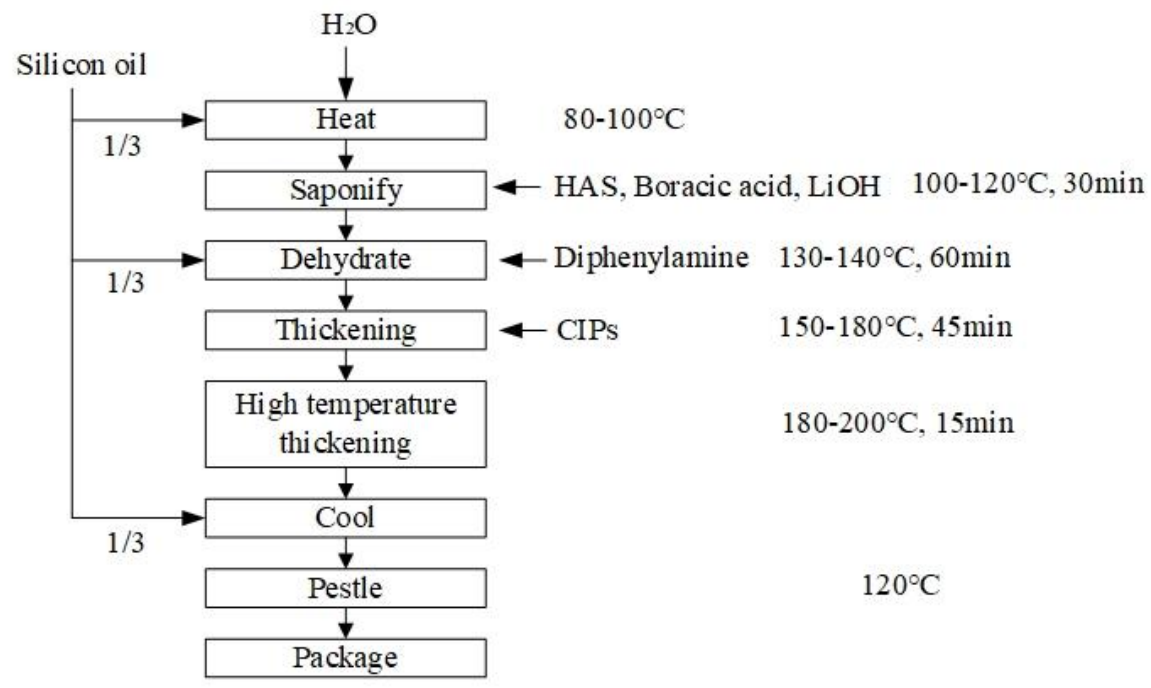

Figure 1. The preparation process of composite lithium-based MR grease. 
Table 1. Material compositions of composite lithium-based MR grease.

\begin{tabular}{|c|c|c|c|c|c|c|c|c|}
\hline \multirow[b]{2}{*}{ Materials } & \multicolumn{8}{|c|}{ Mass(g) } \\
\hline & Sample 1 & Sample 2 & Sample 3 & Sample 4 & Sample 5 & Sample 6 & Sample 7 & Sample 8 \\
\hline Carbonyl iron & \multicolumn{8}{|c|}{90} \\
\hline Silicone oil & \multicolumn{8}{|c|}{30} \\
\hline Diphenylamine & \multicolumn{8}{|c|}{0.1} \\
\hline Lithium thickener & 4.5 & 4.05 & 3.6 & 3.15 & 2.65 & 1.8 & 0.9 & 0 \\
\hline $\begin{array}{l}\text { Lithium stearate/lithium } \\
\text { borate (mass ratio) }\end{array}$ & 10:0 & $9: 1$ & $8: 2$ & $7: 3$ & $6: 4$ & $4: 6$ & $2: 8$ & $0: 10$ \\
\hline
\end{tabular}

\subsection{Performance Test}

The rheological properties of prepared MR grease were characterized by a physical rheometer (MRC 301, Anton Paar Co., Rivoli, Italy) in Figure 2. The diameter of the parallel plate was $20 \mathrm{~mm}$. The gap between the plate and the base was kept at $1 \mathrm{~mm}$ and the temperature was fixed at $25^{\circ} \mathrm{C}$
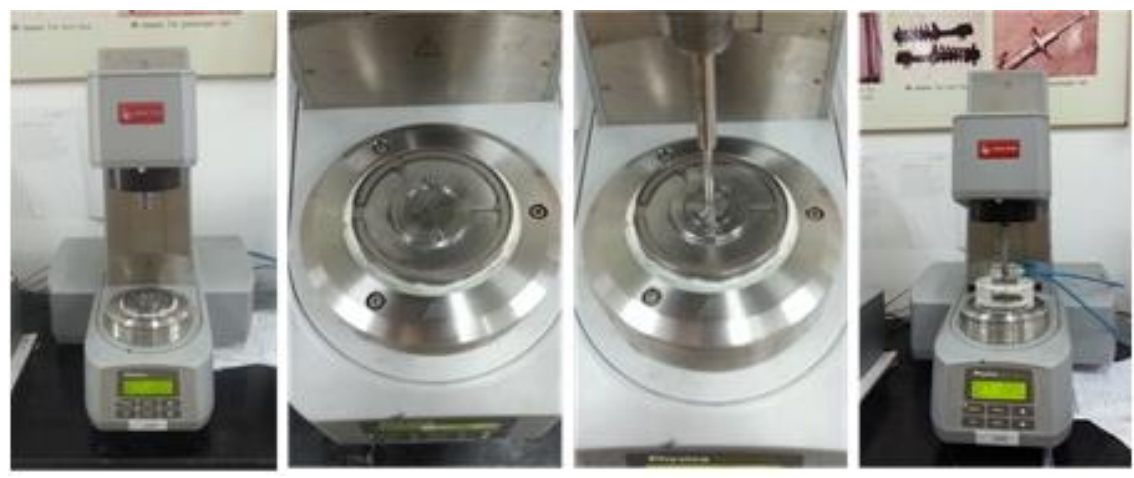

Figure 2. Experimental set-up and test process with MRC 301.

The steady shear test was measured in the shear rate ranging from 0.01 to $100 \mathrm{~s}^{-1}$ and a constant shear of $10 \mathrm{~s}^{-1}$. The magnetic flux density changed from 0 to $1 \mathrm{~T}$ with a step of $0.1 \mathrm{~T}$ by the externally applied currents. In shear mode, the shear stress was measured by the magnetic field scanning. Besides these, the off-state viscosity and shear stress with different shear rates were measured to analyze the MR properties. In oscillation mode, the dynamic performance test was performed in the angular frequency ranging from 0.1 to $100 \mathrm{rad} / \mathrm{s}$. The storage modulus and loss modulus were tested with all samples. In order to ensure the precision of the results, the prepared samples are tested three times. And then, the final experimental results are the average values with three times the results.

\section{Results and Discussion}

\subsection{Rheological Properties}

\subsubsection{Analysis of Off-State Viscosity}

In the steady shear test of shear mode, the relationship between the off-state viscosity and input shear rate is measured with eight MR grease samples which are shown in Figure 3. The prepared MR grease is the non-Newtonian fluid because of the change of the off-state viscosity with all samples. In addition, the off-state viscosity decreases significantly with the increase of the shear rate which is described as the shear thinning behavior. Shear-thinning behavior is a common characteristic with non-Newtonian fluid. The main reason is that the off-state viscosity can be effectively increased by the soap fiber structure of carrier grease under a low shear rate. With the increment of the shear rate, the soap fiber structure with magnetic particles is destroyed by the external shear stress. The viscosity decreases with increasing of the shear rate [30,31]. 


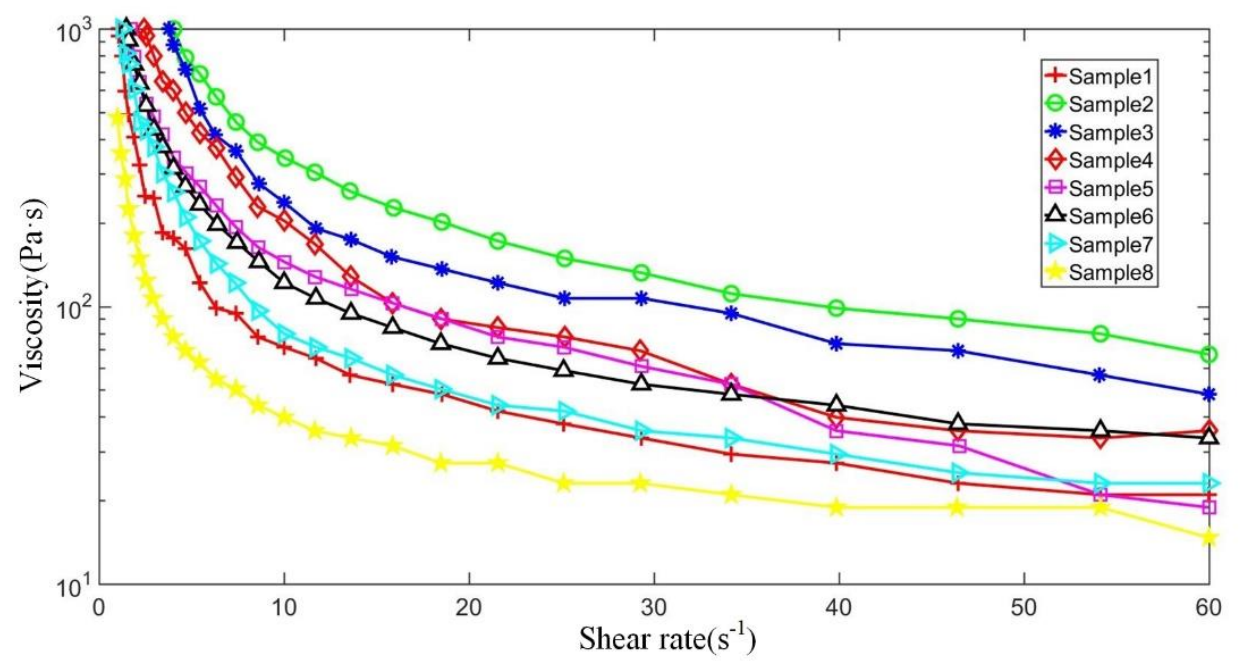

Figure 3. Relationship between off-state viscosity and shear rate.

Compared with experimental results of eight different samples, the viscosities of sample 1 and sample 8 with a single thickener are lower than other composite lithiumbased MR grease samples. The reason for this difference is that the off-state viscosity of MR grease is closely related to the soap fiber structures of the carrier grease matrix. The lithium stearate combined with lithium borate can strengthen the soap fiber structure of the grease matrix under certain conditions with prepared MR grease. The co-crystallization thickening behavior of carrier oil can therefore be realized [32]. Based on these changes of fiber structure in the carrier grease, the off-state viscosity of composite MR grease is larger than conventional MR grease with a single thickener.

Besides these, it can be observed that the off-state viscosity of each prepared sample decreases with the increase of lithium borate content when the shear rate is less than $40 \mathrm{~s}^{-1}$. It is speculated that the decrease is caused by two parts. The first part is that the unreacted lithium borate and the reduction of the content with lithium stearate will decrease the off-state viscosity. Secondly, the thickening behavior caused by the lithium borate is so minimal that can be ignored. And then, there is no significant tendency with off-state viscosity when the shear rate is larger than $40 \mathrm{~s}^{-1}$. With the increase of shear rate, the soap fiber of MR carrier grease is destroyed which results in the change of off-state viscosity [33].

\subsubsection{Analysis of Shear Stress}

The relationship between the shear stress and the magnetic field strength is analyzed under shear mode with the fixed shear rate of $10 \mathrm{~s}^{-1}$ in Figure 4 . The shear stress presents two trends with the increase of magnetic field which involves slow growth region and rapid growth region from Figure 4. The shear stress increases slowly when the magnetic field is less than $0.1 \mathrm{~T}$. And then, the shear stress has rapid growth with the increase of the magnetic field. It is speculated that the internal network structure of soap fiber in the MR carrier grease has a great hindrance effect on the movements of magnetic particles. When the applied magnetic field is minimal, the corresponding magnetic force among magnetic particles is too small to overcome the resistance of carrier grease. Therefore, there is only a short chain of magnetic particles can be formed, and the shear stress increases slowly. When the magnetic flux density is larger than $0.1 \mathrm{~T}$, the corresponding magnetic force among magnetic particles increases greatly. It makes the magnetic particles have enough power to break through the resistance of carrier grease and gradually forms the long-chain or columnar structure which results in the rapid rise of shear stress with the increase of magnetic flux density. 


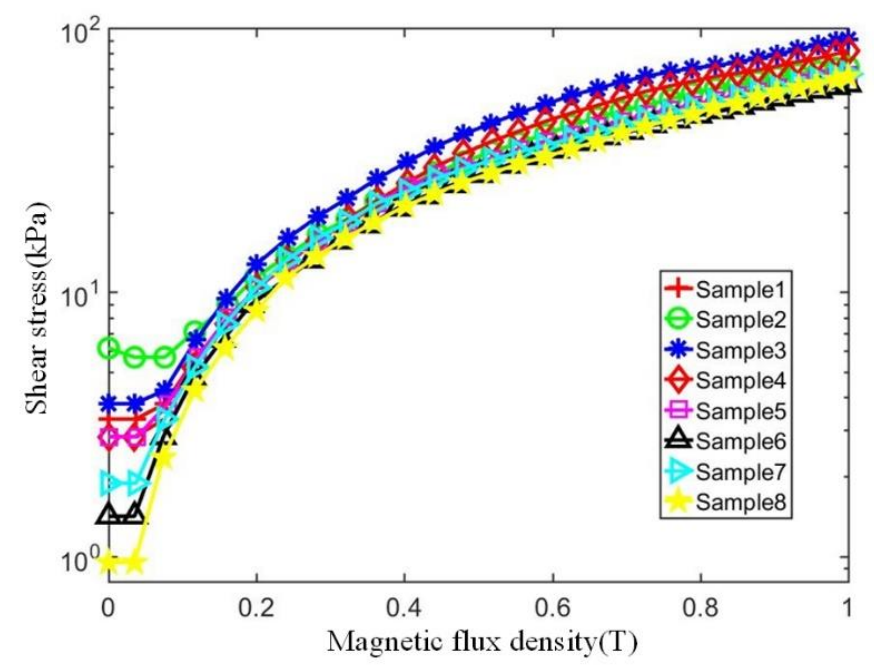

Figure 4. Relationship between shear stress and magnetic flux density at a fixed shear rate of $10 \mathrm{~s}^{-1}$.

According to the experimental results of eight samples, it can be found that the shear stress of sample 3 is the largest under the same magnetic field when the magnetic field is greater than $0.1 \mathrm{~T}$. Under the excitations with a magnetic field of $1 \mathrm{~T}$, the shear stress of sample 3 approaches the value of $91.6 \mathrm{kPa}$ which is increased by $23.6 \mathrm{kPa}$ compared with sample 1 of $68 \mathrm{kPa}$. The minimum shear stress is $61.3 \mathrm{kPa}$ with sample 6 . The maximum shear stress with each sample decreases with increasing the lithium stearate contents. This may be caused by the decrease in viscosity. The shear stress is proportional to the viscosity of MR grease [34].

In the steady shear test, the relationships between shear stress and shear rate with the magnetic flux densities of $0.2 \mathrm{~T}, 0.4 \mathrm{~T}$, and $0.6 \mathrm{~T}$ are shown in Figure 5. It is shown that the shear stress of sample 3 is the largest at all shear rates than any other sample. Compared with different samples, the shear stress of sample 3 is greatly improved and is increased by 2 times, approximately. When the shear rate reaches $100 \mathrm{~s}^{-1}$ and the magnetic flux density is applied with $0.2 \mathrm{~T}, 0.4 \mathrm{~T}$, and $0.6 \mathrm{~T}$, the shear stress reaches the maximum value of $23.5 \mathrm{kPa}, 46.3 \mathrm{kPa}$, and $73.5 \mathrm{kPa}$, respectively. Compared with the shear stress of sample 1 which is $8.7 \mathrm{kPa}, 33.1 \mathrm{kPa}$, and $54 \mathrm{kPa}$, respectively. The shear stress of sample 3 is increased by approximately $170 \%, 39.9 \%$, and $36 \%$, respectively. The increase is possibly due to the difference of internal soap fiber structure with novel crystal form. In the preparation of composite lithium-based MR grease, the co-crystallization between lithium stearate and lithium borate needs a specific mass ratio to make different thickeners react completely. The mixed thickener forms the sheet structure. And then, the generated sheet structure integrates with lithium borate to form the soap fiber structure [34]. When the content of lithium stearate is larger than sample 3, the reaction of co-crystallization is insufficient due to the absence of lithium borate. Therefore, the soap fiber structure is inadequate. Once the content of lithium stearate is less than sample 3, the excess of lithium borate will cause a decrease in the viscosity and the soap fiber structure. The shear stress of sample 3 is far larger than other samples due to the integrity of the internal soap fiber structure.

The flow model with post-yield regions can be described by the Herschel-Bingham model of Equation (1) [20].

$$
\tau=\tau_{y}+k \dot{\gamma}^{n}
$$

where $\tau$ is the total shear force, $\tau_{y}$ is the yield stress of MR grease, $k$ is the consistency coefficient, and $\dot{\gamma}$ is the shear rate, $n$ is the flow behavior index. 


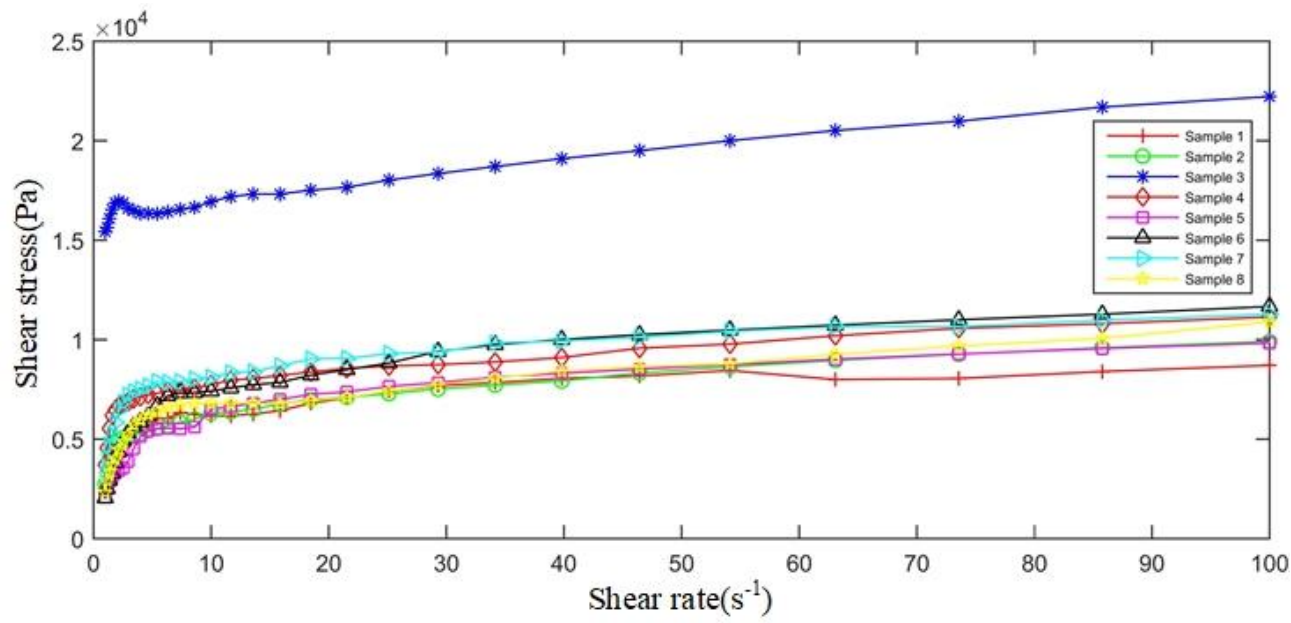

(a)

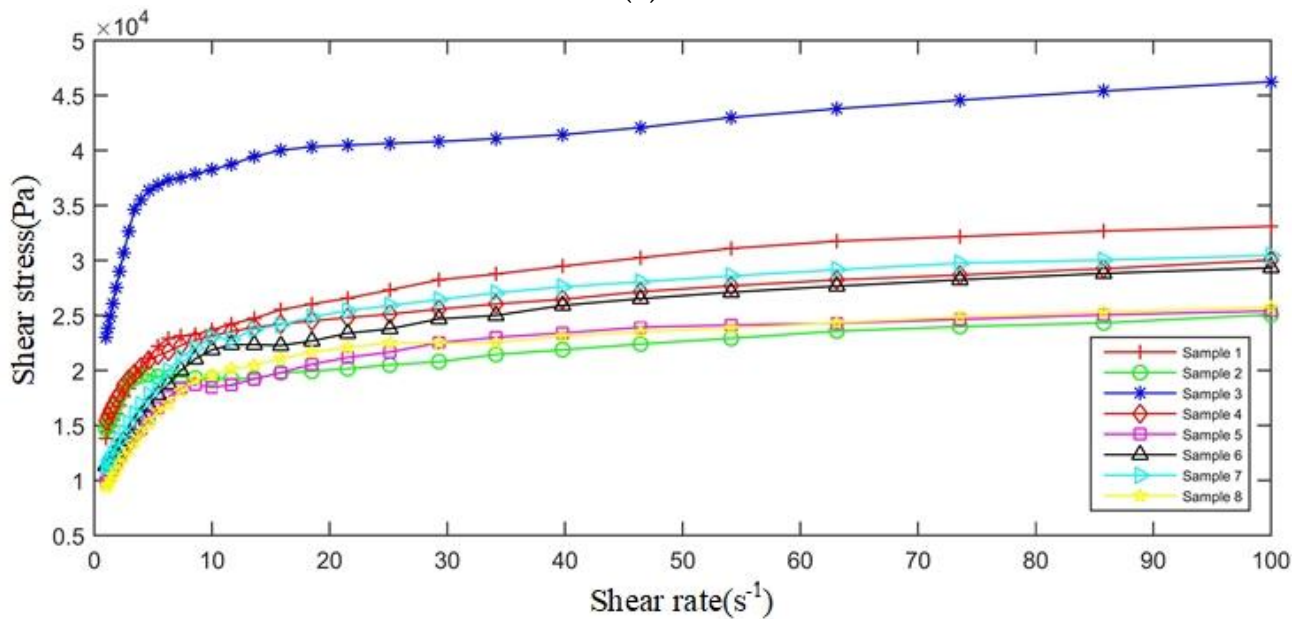

(b)

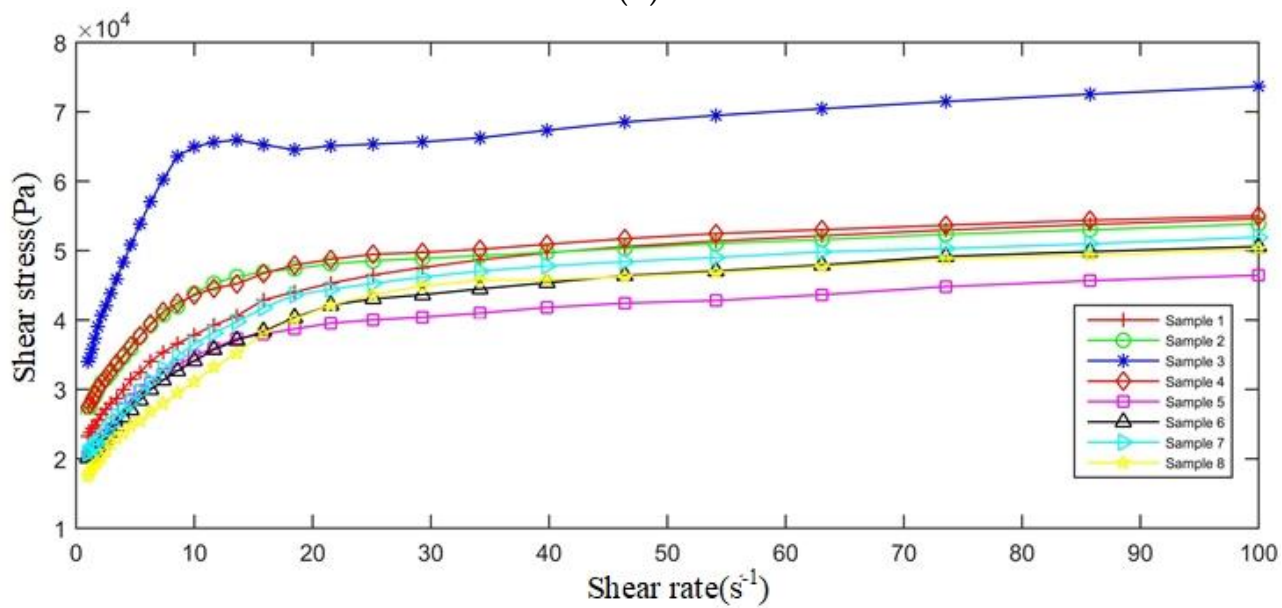

(c)

Figure 5. Relationship between shear stress and shear rate with different magnetic flux densities. (a) magnetic flux density is $0.2 \mathrm{~T}$. (b) magnetic flux density is $0.4 \mathrm{~T}$. (c) magnetic flux density is $0.6 \mathrm{~T}$.

In order to comparatively analyze the shear yield stress between composite MR grease and conventional MR grease with a single thickener, considering the influence of magnetic flux density, the yield shear stress with sample 1 and sample 3 is simulated and shown in Figure 6. The yield shear stress of sample 3 under the applied magnetic fields of $0.2 \mathrm{~T}, 0.4 \mathrm{~T}$, and $0.6 \mathrm{~T}$ is $22.4 \mathrm{kPa}, 48.5 \mathrm{kPa}$, and $72.6 \mathrm{kPa}$, respectively. Compared with the shear stress 
of sample 1 which is $8.4 \mathrm{kPa}, 33 \mathrm{kPa}$, and $54.7 \mathrm{kPa}$, the shear stress of sample 3 is increased by $166.7 \%, 47 \%$, and $32.7 \%$, respectively. This increase is closely related to the internal soap fiber structure of composite MR grease.

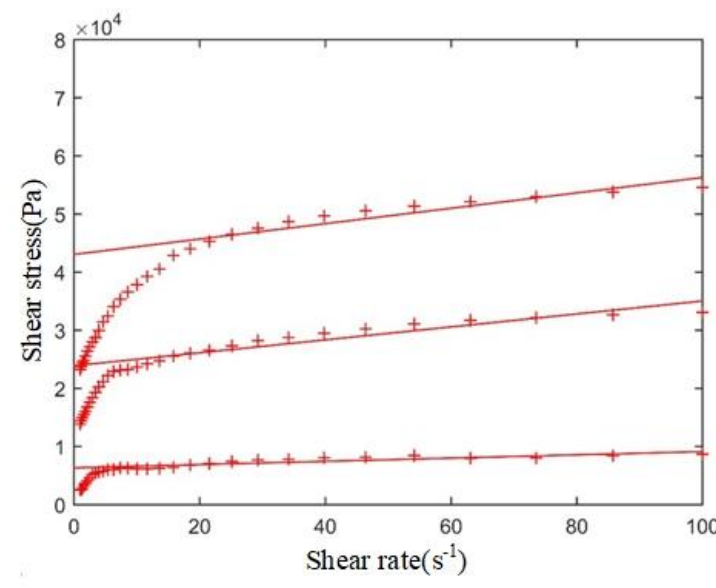

(a)

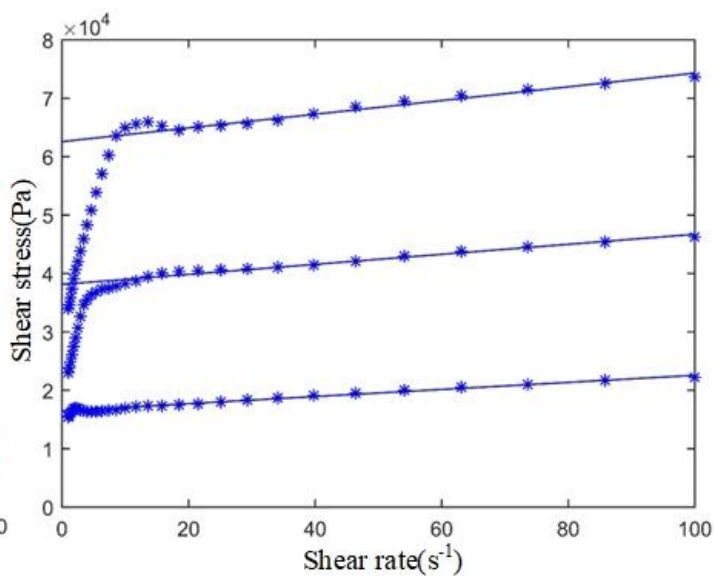

(b)

Figure 6. The simulated curve between shear stress and the shear rate at different magnetic flux densities. (a) sample 1. (b) sample 3 .

In addition, based on the experimental results of prepared composite MR grease, the shear stress curves via shear rates have been fitted by Equation (1). All the key parameters are listed in Table 2.

Table 2. Key parameters of fitting curves between shear stress and shear rates.

\begin{tabular}{ccccc}
\hline Sample & $\begin{array}{c}\text { Magnetic Flux } \\
\text { Density (T) }\end{array}$ & $\begin{array}{c}\text { Yield Shear } \\
\text { Stress } \boldsymbol{\tau}_{\mathbf{y}} \mathbf{( \mathbf { k P a } )}\end{array}$ & $\begin{array}{c}\text { Consistency } \\
\text { Coefficient } \boldsymbol{k}\end{array}$ & $\begin{array}{c}\text { Flow Behavior } \\
\text { Index } \boldsymbol{n}\end{array}$ \\
\hline \multirow{3}{*}{ Sample 1 } & 0.2 & 5.047 & 0.4343 & 0.474 \\
& 0.4 & 24.36 & 0.1572 & 0.9003 \\
Sample 3 & 0.6 & 43.04 & 0.1925 & 0.9112 \\
& 0.2 & 18.94 & 0.3859 & 0.8378 \\
& 0.4 & 37.34 & 0.3219 & 0.7211 \\
\hline
\end{tabular}

The experimental results demonstrate that the shear yield stress of composite lithiumbased MR grease can be significantly improved by adjusting the ratio of mass between lithium stearate and lithium borate. When the mass ratio is 4 between two different thickeners, the soap fiber structure of carrier grease which is caused by the co-crystallization keeps the integrality. Therefore, the proposed composite lithium-based MR grease has the best MR properties than any other mass ratio.

\subsection{Dynamic Viscoelastic Properties}

\subsubsection{Analysis of Storage Modulus}

Under oscillatory shear mode, the relationship between storage modulus and magnetic flux density is investigated when the shear strain is $0.1 \%$ and the angular frequency is $10 \mathrm{~s}^{-1}$. As shown in Figure 7, with the increase of the magnetic field, the storage moduli of eight MR grease samples are divided into three regions which are in agreement with the research works in literature [13]. The storage moduli will increase rapidly with the increase of the magnetic flux density when the magnetic flux density is beyond $0.1 \mathrm{~T}$. Finally, the storage modulus tends to be stable. Because of the carrier grease is the viscoelastic materials [33]. The proposed composite MR grease will show viscoelastic properties. Under the fixed shear rate, composite MR grease works in the post-yield state when the magnetic flux density 
is less than $0.1 \mathrm{~T}$. The storage modulus will keep constant with a lower storage modulus. Once the magnetic flux density is larger than $0.1 \mathrm{~T}$, the composite MR grease works in the transition state between the pre-yield and post-yield state. The storage modulus increases with increasing the magnetic flux density. Finally, the saturation magnetization of the magnetic particles reaches the maximum by the external magnetic field excitation. The composite MR grease works in the post-yield state and the storage modulus will keep constant again.

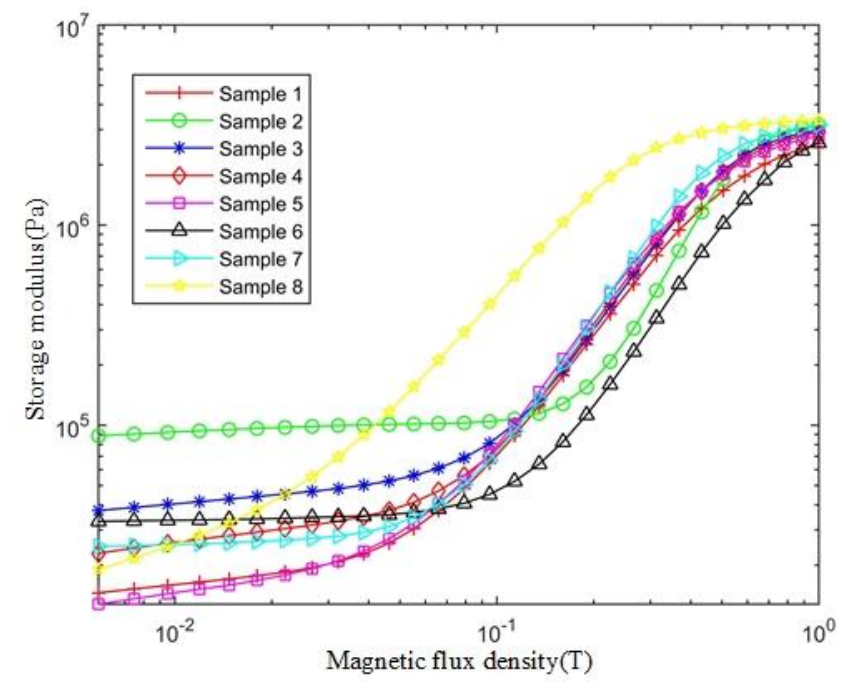

Figure 7. Relationship between storage modulus and magnetic flux density with a fixed shear strain of $0.1 \%$.

Besides these, the MR effect is defined as

$$
\frac{\Delta G^{\prime}}{G_{0}{ }^{\prime}}=\frac{G_{m a x}{ }^{\prime}-G_{0}{ }^{\prime}}{G_{0}{ }^{\prime}} \times 100 \%
$$

where $G_{\max }{ }^{\prime}$ is the maximum storage modulus with eight samples. $G_{0}{ }^{\prime}$ is the off-state storage modulus with eight samples.

The MR effects of eight samples are shown in Table 3. It can be observed that the MR effect of sample 2 is the lowest compared with other samples. The MR effects of almost all samples are larger than $8400 \%$. Compared with MR grease with a single thickener, the maximum MR effect of composite MR grease is $23,600 \%$ with sample 5 which is increased by $19.1 \%$ than sample 1 . Compared with the MR effects of sample 2 , the maximum value is increased by $521 \%$. It shows that the MR effect of composite lithium-based MR grease can be significantly improved by adjusting the mass ratio between lithium stearate and lithium borate.

Table 3. Magnetorheological effect of eight samples.

\begin{tabular}{ccccccccc}
\hline Sample & $\mathbf{1}$ & $\mathbf{2}$ & $\mathbf{3}$ & $\mathbf{4}$ & $\mathbf{5}$ & $\mathbf{6}$ & $\mathbf{7}$ & $\mathbf{8}$ \\
\hline $\begin{array}{c}\text { Magnetorheological } \\
\text { effect(\%) }\end{array}$ & 19,800 & 3800 & 8400 & 13,600 & 23,600 & 8600 & 13,400 & 18,200 \\
\hline
\end{tabular}

\subsubsection{Analysis of Loss Modulus and Angular Frequency}

When the shear strain is fixed at $0.1 \%$ and the magnetic flux density is fixed at off-state and $1 \mathrm{~T}$, the relationships between loss modulus and angular frequency are shown in Figure 8. It can be observed that the loss modulus of eight MR grease samples increases with the increase of angular frequency at off-state. However, the loss modulus decreases with the increase of angular frequency under magnetic flux density of $1 \mathrm{~T}$. The 
variation laws of loss modulus are consistent with eight MR grease samples under the same magnetic excitations.

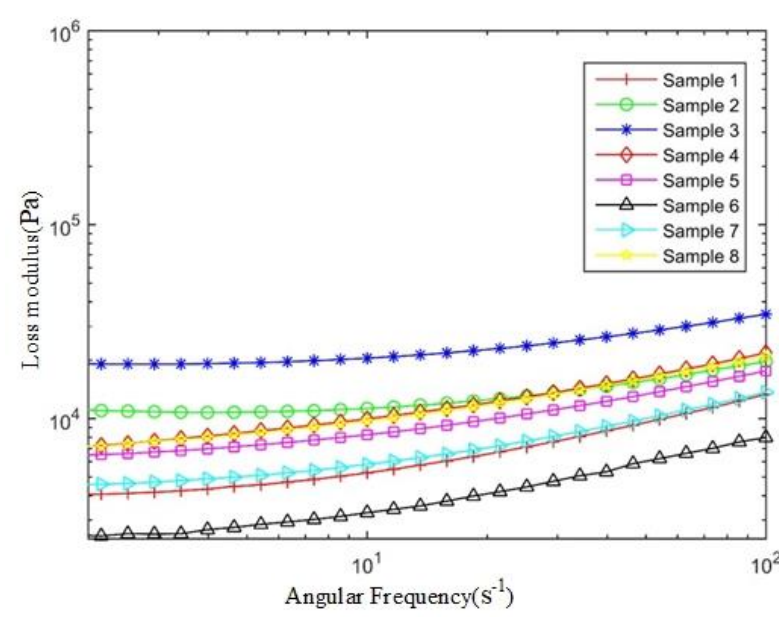

(a)

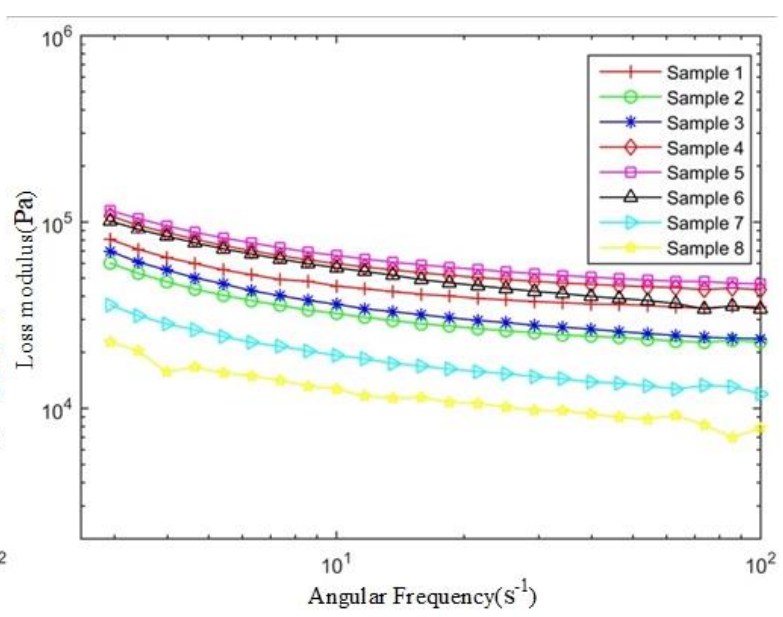

(b)

Figure 8. Relationship between loss modulus and angular frequency at a fixed shear strain of $0.1 \%$. (a) off-state. (b) $1 \mathrm{~T}$.

According to the literature [13], the variation laws of storage modulus and loss modulus with angular frequency are the same essentially under different excitations. The theorems are different from the experimental results of the prepared composite MR grease in this paper. It is speculated that the composite lithium-based MR grease which has been prepared in this paper has large consistency and iron powder content. Under the excitations of the magnetic field, the soap fibers in the composite MR grease are confined by the magnetic particle chain or cylindrical structure. The soap fiber structure of the proposed composite MR grease is strengthened and the variation laws between loss modulus and angular frequency are changed.

In order to further verify the rheological behaviors with composite lithium-based MR grease, the rheological behaviors are compared with other literature in Table 4. Some key performance parameters are listed to be comparatively analyzed. As shown in Table 4, compared with the literature [14], the shear yield stress and MR effect of composite MR grease have been improved significantly. The shear yield stress is increased by $710 \%$ and the MR effect is increased by $466.3 \%$. Comparing the MR grease of literature [15,28], the composite MR grease can effectively improve the rheological behaviors. However, compared with different samples with different mass ratios, the shear yield stress and MR effect are difficult to satisfy simultaneously.

Table 4. Comparison of rheological properties with other MR grease.

\begin{tabular}{ccc}
\hline Rheological Properties & Shear Yield Stress (kPa) & MR Effect (\%) \\
\hline Literature [13] & 6.389 & $5061 \%$ \\
Literature [15] & 49.7 & - \\
Literature [28] & 52.7 & $592.38 \%$ \\
Sample 3 of this paper & 72.6 & $8400 \%$ \\
Sample 5 of this paper & 45.4 & $23,600 \%$ \\
\hline
\end{tabular}

\section{Conclusions}

In this paper, a novel composite lithium-based MR grease is prepared experimented with and analyzed with different mass ratios between lithium stearate and lithium borate. According to the experimental results with eight samples, the composite lithium-based MR grease has a significant improvement in rheological behaviors compared with the MR grease of a single thickener. 
1. Under the off-state of the magnetic field, the prepared composite MR grease has typical shear thinning characteristics. At a low shear rate which is less than $40 \mathrm{~s}^{-1}$, the viscosity of composite MR grease decreases with the increase of lithium borate content.

2. With the increase of the magnetic field, the increase of shear stress with prepared composite lithium-based MR grease can be divided into two regions which are the slow growth region and rapid growth region. Compared with the MR grease of a single thickener, the shear stress of the composite lithium-based MR grease is significantly improved. The maximum shear stress is increased from $54 \mathrm{kPa}$ to $73.5 \mathrm{kPa}$ with a magnetic field of $0.6 \mathrm{~T}$.

3. Comparing the MR grease with a single thickener, the shear yield stress of composite MR grease can be improved by adjusting the ratio of mass between lithium stearate and lithium borate. When the magnetic field is $0.6 \mathrm{~T}$, the shear yield stress increased from $54.7 \mathrm{kPa}$ to $72.6 \mathrm{kPa}$. The shear yield stress of composite MR grease with a mass ratio of 4 is increased by $166.7 \%$ with a magnetic field of $0.2 \mathrm{~T}$.

4. Compared with the MR grease of a single thickener, the prepared composite lithiumbased MR grease has been promoted with MR effect. When the shear strain is fixed at $0.1 \%$, the maximum MR effect reaches $23,600 \%$ which is increased by $19.1 \%$ than that of MR grease with a single thickener.

Besides these, it is found that the variations between the loss modulus and angular frequency with prepared composite MR grease are inconsistent with other investigations. The main reason may be that the prepared composite lithium-based MR grease has a higher consistency and carbonyl iron powder content. It needs to be further studied.

Author Contributions: P.L. prepared and wrote the original manuscript; H.Y. supervised the whole research work, contributed to writing and reviewing the manuscript, and acquired funding; C.D. carried out the experiments and took part in the analysis of the data; X.D. was supervision and involved in review and editing. All authors have read and agreed to the published version of the manuscript.

Funding: This work has been supposed by the Chongqing University Graduate Student Research Innovation Project (CYB21012).

Institutional Review Board Statement: Not applicable.

Informed Consent Statement: Informed consent was obtained from all subjects involved in the study.

Data Availability Statement: The raw/processed data required to reproduce these findings cannot be shared at this time as the data is also part of an ongoing study.

Conflicts of Interest: The authors declare no conflict of interest.

\section{References}

1. Dyke, S.J.; Spencer, B.F.; Sain, M.K.; Carlson, J.D. Modeling and control of magnetorheological dampers for seismic response reduction. Smart Mater. Struct. 1996, 5, 565-575. [CrossRef]

2. Choi, S.B.; Hong, S.R.; Sung, K.G.; Sohn, J.W. Optimal control of structural vibrations using a mixed-mode magnetorheological fluid mount. Int. J. Mech. Sci. 2008, 50, 559-568. [CrossRef]

3. Dong, X.M. Semi-active control of magneto-rheological variable stiffness and damping seat suspension with human-body model. Int. J. Veh. Des. 2013, 63, 119-136. [CrossRef]

4. Nguyen, S.D.; Choi, S.B.; Nguyen, Q.H. A new fuzzy-disturbance observer-enhanced sliding controller for vibration control of a train-car suspension with magnetorheological dampers. Mech. Syst. Signal. Process. 2018, 105, 447-466. [CrossRef]

5. Weber, F.; Distl, H. Amplitude and frequency independent cable damping of Sutong Bridge and Russky Bridge by magnetorheological dampers. Struct. Control. Health Monit. 2015, 22, 237-254. [CrossRef]

6. Yang, J.; Sun, S.S.; Tian, T.F.; Li, W.H.; Du, H.P.; Alici, G.; Nakano, M. Development of a novel multi-layer MRE isolator for suppression of building vibrations under seismic events. Mech. Syst. Signal. Process. 2016, 70-71, 811-820. [CrossRef]

7. Casciati, F.; Rodellar, J.; Yildirim, U. Active and semi-active control of structures-Theory and applications: A review of recent advances. J. Intell. Mater. Syst. Struct. 2012, 23, 1181-1195. [CrossRef]

8. Díaz. Tena, E.; Marcaide, L.; Góme, F.J.; Chaires Bocanegra, D.L. Use of Magnetorheological Fluids for Vibration Reduction on the Milling of Thin Floor Parts. Procedia Eng. 2013, 63, 835-842. [CrossRef] 
9. Urreta, H.; Aguirre, G.; Kuzhir, P.; Lacalle, L.D. Seals Based on Magnetic Fluids for High Precision Spindles of Machine Tools. Int. J. Precis. Eng. Manuf. 2018, 19, 495-503. [CrossRef]

10. Urreta, H.; Aguirre, G.; Kuzhir, P.; Lacalle, L.D. Actively lubricated hybrid journal bearings based on magnetic fluids for high-precision spindles of machine tools. J. Intell. Mater. Syst. Struct. 2019, 30, 2257-2271. [CrossRef]

11. Puma-Araujo, S.D.; Olvera-Trejo, D.; Martínez-Romero, O.; Urbikain, G.; Elías-Zúñiga, A.; Lacalle, L.N. Semi-Active Magnetorheological Damper Device for Chatter Mitigation during Milling of Thin-Floor Components. Appl. Sci. 2020, $10,5313$. [CrossRef]

12. Park, B.O.; Park, B.J.; Hato, M.J.; Choi, H.J. Soft magnetic carbonyl iron microsphere dispersed in grease and its rheological characteristics under magnetic field. Collid Polym. Sci. 2011, 289, 381-386. [CrossRef]

13. Kintz, A.K.; Carlson, D.J.; Munoz, B.C.; Sessoms, J.D. Magnetorheological grease composition. USP 2003, 6547986, B1.

14. Wang, H.; Zhang, G.; Wang, J. Quasi-Static Rheological Properties of Lithium-Based Magnetorheological Grease under Large Deformation. Material 2019, 15, 2431. [CrossRef] [PubMed]

15. Sahin, H.; Gordaninejad, F.; Wang, X.; Fuchs, A. Rheological behavior of magnetorheological grease (MRG). Proceeding SPIE Act. Passiv. Smart Struct. Integr. Syst. 2007, 6525, 1-9.

16. Sahin, H.; Wang, X.; Gordaninejad, F. A New Model for Yield Stress of Magnetorheological Greases/Gels under Combined Effects of Magnetic Field and Temperature. Proceeding SPIE Act. Passiv. Smart Struct. Integr. Syst. 2009, 7288, 1-9.

17. Kim, J.E.; Ko, J.D.; Liu, Y.D.; Kim, I.G.; Choi, H.J. Effect of Medium Oil on Magnetorheology of Soft Carbonyl Iron Particles. Magn. IEEE Trans. Magn. Mag. 2012, 48, 3442-3445. [CrossRef]

18. Mohamad, N.; Ubaidillah; Mazlan, S.A.; Ubaidillah; Choi, S.B.; Aziz, S.A.A.; Sugimoto, M. The Effect of Particle Shapes on the Field-Dependent Rheological Properties of Magnetorheological Greases. Materials 2019, $20,1525$.

19. Wang, K.J.; Dong, X.M.; Li, J.L.; Shi, K.Y.; Li, K.J. Effects of Silicone Oil Viscosity and Carbonyl Iron Particle Weight Fraction and Size on Yield Stress for Magnetorheological Grease Based on a New Preparation Technique. Materials. 2019, 12, 1778. [CrossRef]

20. Prasad, M.H.; Gangadharan, K.V. Synthesis and Magneto Mechanical Properties of MR Grease. Int. J. Eng. Res. Technol. 2014, 3, 2369-2372.

21. Park, J.H.; Kwon, M.H.; Park, O.O. Rheological Properties and Stability of Magnetorheological Fluids using Viscoelastic Medium and Nanoadditives. Korean J. Chem. Eng. 2001, 18, 580-585. [CrossRef]

22. Hu, Z.D.; Yan, H.; Wang, X.M.; Yang, J.J.; Guo, J.J. The effect of soap content on the rheology of mineral oil-based magnetorheological grease. J. Funct. Mater. 2015, 2, 02105-02108.

23. Wang, K.J.; Dong, X.M.; Li, J.L.; Shi, K.Y. Yield dimensionless magnetic effect and shear thinning for magnetorheological grease. Results Phys. 2020, 18, 103328. [CrossRef]

24. Mohamad, N.; Ubaidillah; Mazlan, S.A.; Imaduddn, F.; Choi, S.B.; Yazid, I. A comparative work on the magnetic field-dependent properties of plate-like and spherical iron particle-based magnetorheological grease. PLoS ONE 2018, 13, 0191795. [CrossRef]

25. Yao, L.D.; Yang, H.N.; Sun, H.W.; Duan, Q.H. Research of Rheology for the Lithium Grease. Acta Pet. Sin. 2011, $1001-8719$.

26. Zeng, H.; Chen, X.N.; Chen, Z.; Ji, H.B. Influence of Composition of Complex Lithium-based Lubricant Grease on the Microstructure. Lubr. Eng. 2011, 36, 42-47.

27. Yan, M.; Meng, K.; Wu, J.; Zhou, Y.; Yang, W. Rheological property of composite lithium based magnetorheological grease based on poly-alapha olefin synthetic base oil. Mater. Mech. Eng. 2021, 45, 20-24.

28. Mohamad, N.; Mazlan, S.A.; Ubaidillah; Choi, S.B.; Nordin, M.F.M. The Field-Dependent Rheological Properties of Magnetorheological Grease Based on Carbonyl-Iron-ParticleS. Smart Mater. Struct. 2016, 25, 10. [CrossRef]

29. Nasir, N.; Nazmi, N.; Mohamad, N.; Ubaidillah, U.; Nordin, N.A.; Mazlan, S.A.; Aziz, S.; Shabdin, M.; Yunus, N. Rheological Performance of Magnetorheological Grease with Embedded Graphite Additives. Materials 2021, 14, 5091. [CrossRef] [PubMed]

30. Bao, W.; Dario, C.; Chen, J.B. Delay of re-entanglement kinetics by shear-induced nucleation precursors in isotactic polypropylene melt-ScienceDirect. Polymer 2020, 210, 123000.

31. Castillo-Tejas, J.; Castrejón-González, O.E.; Carro, S.; Gonzalez-Coronel, V.; Alvarado, J.; Manero, O. Associative polymers. Part III: Shear rheology from molecular dynamics. Colloids Surf. A Physicochem. Eng. Asp. 2016, 491, 37-49. [CrossRef]

32. Zhu, T.B. Encyclopedia of grease technology. China Petrochem. Press. 2004, 479-480.

33. Yang, G.; Zheng, T.; Cheng, Q.H.; Zhang, H.C. Molecular dynamics simulation on shear thinning characteristics of non-Newtonian fluids. Acta Phys. Sin. 2021, 70, 124701.

34. Dai, J.; Chang, H.; Zhao, R.; Huang, J.; Li, K.Q.; Xie, S.P. Investigation of the relationship among the microstructure, rheological properties of MR grease and the speed reduction performance of a rotary micro-brake. Mech. Syst. Signal. Process. 2019, 116, 741-750. [CrossRef] 